\title{
El Triunfo de la Eucaristía en algunas estampas de libros litúrgicos españoles de finales del siglo XVI e inicios del XVII
}

\author{
The Triumph of the Eucharist in some prints of Spanish \\ liturgics books of late 16th century and early 17th century
}

Juan CALVO PORTELA

Universidad Complutense de Madrid

Recibido: 18-III-2016

Aceptado: 27-IV-2016

RESUMEN: En el presente artículo abordamos el estudio de una serie de estampas en las que se representa el motivo del Triunfo de la Eucaristía que sirvieron para acompañar a la fiesta del Corpus Christi en algunos libros litúrgicos salidos de la imprenta de Guillermo Foquel en Salamanca y de la Imprenta Real de Madrid, dirigida por los Junta, de finales del siglo XVI e inicios del XVII.

Palabras clave: Eucaristía, Triunfo, Libros litúrgicos, Imprenta, Concilio de Trento.

ABSTRACT: In the present article we approach the study of a series of prints in which the motif of the Triumph of the Eucharist is represented. These motifs served for going along with the festivity of the Corpus Christi in some liturgical books that were printed in the printing house of Guillermo Foquel in Salamanca and the Royal Press in Madrid, managed by Junta, in late $16^{\text {th }}$ century and the beginning of the $17^{\text {th }}$ century.

Keywords: Eucharist, Triumph, Press, Liturgic books, Council of Trent.

\section{EL MOTIVO DEL TRIUNFO DE LA EUCARISTÍA EN EL CONTEXTO TRI- DENTINO}

Los sacramentos en general, y la Eucaristía en particular, constituyeron uno de los principales puntos de fricción entre los reformadores protestantes y los católicos. Los reformadores negaron o modificaron algu- nas de las doctrinas defendidas por la Iglesia sobre la Eucaristía desde hacía siglos, como la transubstanciación, la presencia real y substancial de Cristo en cuerpo y alma en las especies eucarísticas, el carácter sacrificial de la Misa, su capacidad redentora o la potestad de la Iglesia para administrar los sacramentos y de manera específica la Eucaristía. Aunque los reformadores no tuvieron una 
doctrina unificada acerca de este sacramento, prueba de ello son las posturas abiertamente enfrentadas de Lutero y Zwinglio en torno a las doctrinas de la consubstanciación y de la presencia real de Cristo en los accidentes del pan y del vino. Calvino que trató de conciliar ambas posturas, finalmente pareció inclinarse hacia una concepción más próxima a la del reformador suizo.

Los sacramentos fueron uno de los temas que se abordaron durante el Concilio de Trento, siendo el de la Eucaristía al que se prestó mayor atención. En los decretos sobre la misma se defendieron aquellos dogmas que los reformadores habían negado o modificado. Las artes se van a convertir en el instrumento ideal para dar a conocer y explicar a los creyentes estos dogmas, muchos de ellos de una enorme complejidad teológica, siguiendo lo establecido en la última sesión conciliar.

Uno de los motivos que tuvo un mayor desarrollo en el arte postridentino fue el de la Disputa o Triunfo de la Eucaristía, porque como señaló Mâle, el Triunfo del Sacramento va a ser la mayor expresión del triunfo de la propia Iglesia ${ }^{1}$. En las representaciones del mismo hallamos a los Padres de la Iglesia junto a otros grandes santos como santo Tomás de Aquino o san Francisco de Asís debatiendo acaloradamente sobre la transubstanciación y la presencia real de Cristo en las especies eucarísticas ${ }^{2}$, que obviamente tenemos que poner en relación con la defensa que hizo la Iglesia del culto a los santos que en parte se explica por su fervor por la Eucaristía. Además, el Sacramento constituye el nexo entre la Iglesia Triunfal del Cielo y la Iglesia militante de la Tierra, incidiéndose en la potestad de ésta para administrar el sacramento. En el decreto sobre la Verdadera

${ }^{1}$ E. MÂLE, El arte religioso de la Contrarreforma, Madrid, 2001, p. 82.

${ }^{2}$ M. VLOBERG, L'Eucharistie dans l'art, Grenoble, 1946, pp. 249 y 253; E. MÂLE, Op. cit., pp. 83-84; J. B. KNIPPING, Iconography of the counter reformation in the Netherlands, Leiden, 1974, Vol. 2, p. 307; L. RÉAU, Iconografía del arte Cristiano, Barcelona, 2001, Vol.1, p. 548. y católica doctrina del sacramento del Orden, aprobada en la Sesión XXIII del Concilio, se insistió en este aspecto: "Habiendo pues recibido la Iglesia católica, por institución del Señor, en el Nuevo Testamento, el santo y visible sacrificio de la Eucaristía; es necesario confesar también, que hay en la Iglesia un sacerdocio nuevo, visible y externo, en que se mudó el antiguo. Y que el nuevo haya sido instituido por el mismo Señor y Salvador, y que el mismo Cristo haya también dado a los Apóstoles y sus sucesores en el sacerdocio la potestad de consagrar, ofrecer y administrar su cuerpo y su sangre $(. . .)^{\prime \prime 3}$.

Por otro lado, este motivo también hace hincapié en la importancia de la veneración y adoración de la Eucaristía, puesto que los santos que acuden a este cónclave lo hacen para venerarla, sirviendo de modelo a los fieles. El Concilio hizo referencia a la importancia de la adoración del Sacramento en el capítulo quinto del decreto Sobre el Santísimo Sacramento de la Eucaristía: "No queda, pues, motivo alguno de duda en que todos los fieles cristianos hayan de venerar a este Santísimo Sacramento, y prestarle, según costumbre siempre recibida en la Iglesia católica, el culto de latría que se debe al mismo Dios. $\mathrm{Ni}$ se le debe tributar menos adoración con el pretexto de que fue instituido por Cristo nuestro Señor para recibirlo: pues creemos que está presente en él aquel mismo Dios de quien el Padre Eterno, introduciéndole en el mundo, dice: Adórenle todos los Ángeles de Dios $(\ldots)^{\prime \prime}$.

De sobra es sabido que en el desarrollo del mismo tuvo una importancia absolutamente crucial uno de los frescos que Rafael

\footnotetext{
3 "Decreto de la Verdadera y católica doctrina del sacramento del Orden", en "De la institución del sacerdocio de la Nueva Ley", Capítulo I, Sesión XXIII, del 15 de julio de 1563, de El Sacrosanto y ecuménico Concilio de Trento (traducción de Ignacio López de Ayala), París, 1857, p. 267.

4 "Decreto del Santísimo Sacramento de la Eucaristía", en "Del culto y veneración que se debe de dar a este Santísimo Sacramento", Capítulo V, Sesión XIII, del 11 de octubre de 1563, en El Sacrosanto y ecuménico..., p. 128.
} 
hizo para decorar la Stanza della Segnatura del Vaticano, hacia el año 1509, por encargo de Julio II. El genio de Urbino plasmó en su obra algunos de los aspectos que mayor transcendencia van a adquirir para la Iglesia a partir del segundo decenio del siglo XVI como la transubstanciación y la presencia real de Cristo en cuerpo y alma en el Sacramento, anticipándose casi en una década al inicio de la Reforma y respondiendo por adelantado a las críticas de los reformadores sobre la doctrina de la Eucaristía. Las cuestiones planteadas eran de gran relevancia contemporánea, pero ya se habían tratado durante el medievo; por ejemplo Guillermo de Occam había considerado que la consubstanciación no sólo era una alternativa teológica posible, sino que planteaba menos dificultades que la transubstanciación ${ }^{5}$. Además algunos herejes tardo-medievales como Wycliff o Hus habían expresado opiniones contrarias a la doctrina de la Iglesia sobre la Eucaristía, aunque Hus nunca llegó a defender la postura de Wycliff contraria a la transubstanciación, como se desprende de su tratado De corpore Christi ${ }^{6}$. Durante los siglos XV y XVI algunos de los concilios de reforma como el Lateranense y el de Florencia ${ }^{7}$ abordaron la discusión sobre la transubstanciación, pero las posturas enfrentadas entre los conciliaristas y el Papa hizo que muchos de los decretos aprobados en dichos concilios nunca llegaran a ser ratificados por el Pontífice y menos aún aplicados. Además para el Papa Julio II, que encargó los frescos a Rafael, la Eucaristía se convirtió en uno de los temas centrales de su pontificado.

La fama de los frescos de Rafael, sobre todo de La Escuela de Atenas y del Triunfo de la

${ }^{5}$ S. GÓMEZ NAVARRO, "La Eucaristía en el corazón del siglo XVI", Hispania Sacra, LVIII, no 118, 2006, p. 505.

${ }^{6}$ V. A. ÁLVAREZ PALENZUELA, “El pontificado de Bonifacio VIII a Alejandro VI", en E. MITRE FERNÁNDEZ (coord.), Historia del Cristianismo. Vol. 2. El Mundo medieval. Granada, 2004, p. 668.

${ }^{7}$ Catecismo del Santo Concilio de Trento para los párrocos, Cuenca, 1803, p. 213.
Eucaristía, le debió mucho a las estampas, ya que se van a reproducir en un sinfín de láminas de cobre que se extienden por toda Europa y el Nuevo Mundo. Fue el propio pintor el primero en percatarse de la capacidad de la estampa como un instrumento para extender su prestigio y dar a conocer sus obras ${ }^{8}$. Entre las estampas que se hicieron del Triunfo de la Eucaristía podemos mencionar la que abrió el grabador mantuano Giorgio Ghisi y editó el amberino Jêrome Cock, que se puede fechar entre 1550 y $1551^{9}$. Esta estampa a su vez fue copiada por otro grabador italiano, Gaspare Oselli, de la que hizo una tirada uno de los editores venecianos más importantes de toda la centuria, Nicola Nelli ${ }^{10}$.

Aunque no fue el fresco de Rafael, ni las estampas que se hicieron de él, los que inspiraron las estampas que ilustran algunos libros litúrgicos del Nuevo Rezado que se imprimieron en España a fines del siglo XVI y en las primeras décadas de la siguiente centuria, que son nuestro principal objeto de estudio, sino que este papel lo tuvo una estampa del grabador flamenco Cornelio Cort, asentado en Roma, basada en un diseño de Federico Zuccaro, editada por Lorenzo Vaccarius en Roma en 1575, tal como indica la dedicatoria del margen inferior. El dibujo del pintor italiano se conserva actualmente en el Museo Nacional de Estocolmo ${ }^{11}$ y se fecha hacia $1573^{12}$. En la Biblioteca Nacional de España se conserva un ejemplar de la estampa, del primer estado de cuatro (Fig. 1) ${ }^{13}$.

\footnotetext{
${ }^{8}$ A. ÁVILA PADRÓN, “Influencia de Rafael en la pintura y la escultura española del siglo XVI a través de estampas", Archivo Español de Arte, 1984, p. 66.

${ }^{9}$ Biblioteca Nacional de Francia, EC-34 (B)-FOL, Inventario $183,512 \times 854 \mathrm{~mm}$.

${ }^{10}$ Real Biblioteca del Monasterio del Escorial, Signatura Escorial, 28-I-1. Fol. 121r., 507×835 mm.

${ }^{11}$ Museo Nacional de Estocolmo, $\mathrm{n}^{\mathrm{o}}$ inventario 514.

${ }^{12} \mathrm{~J}$. C. J. BIERENS DE HAAN, L'oeuvre gravé de Cornelis Cort, graveur hollandais, 1533-1578, La Haye, 1948, p. 120.

${ }^{13}$ Biblioteca Nacional de España (en adelante BNE), Sala Goya, Inventario 1842, 507×321 mm.
} 


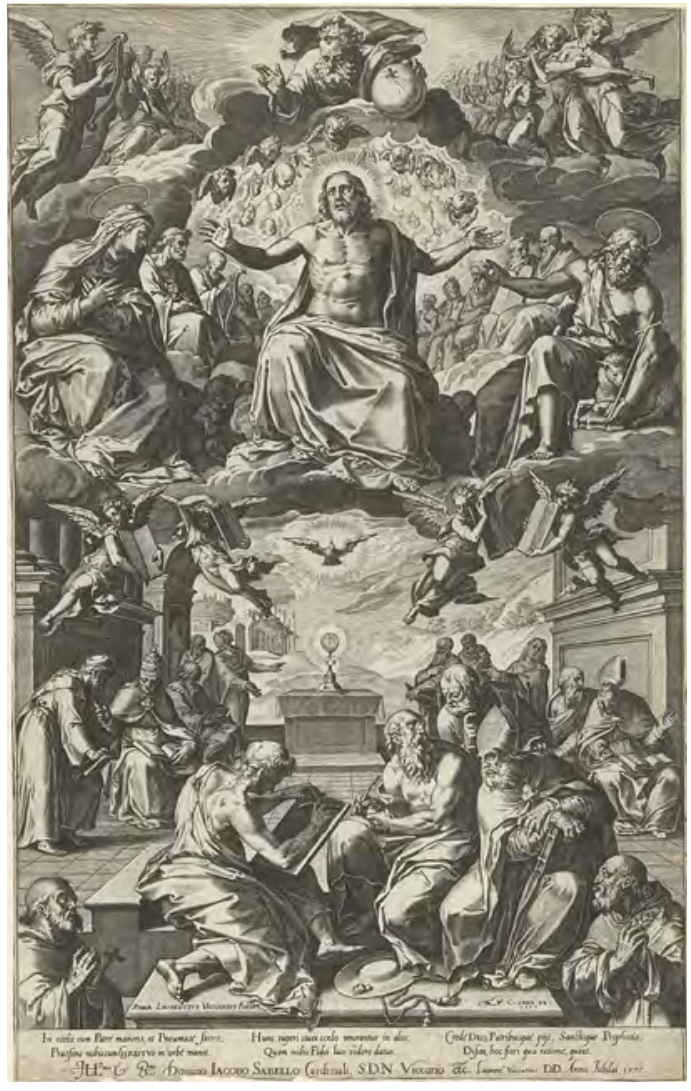

- Fig. 1. Federico Zuccaro. “Triunfo de la Eucaristía", abierta por Conelio Cort. Primer estado de cuatro. Biblioteca Nacional de España, Sala Goya, Invent/1842. Talla dulce, $507 \times 321$ $\mathrm{mm}$.

Es indudable que Zuccaro tuvo presente el fresco de Rafael a la hora de realizar su dibujo, del que tomó no sólo el motivo iconográfico, sino la composición general. Al igual que éste se estructura en dos partes, la celestial y la terrenal, en las que se disponen respectivamente la Iglesia Triunfal y la militante, unidas por medio de la Eucaristía. En esta imagen cobra una especial relevancia la presencia de la Trinidad celestial y la Trinidad terrenal que subrayan el sentido cristocéntrico de la doctrina eucarística defendida por Trento, y la doble naturaleza de Cristo, humana y divina, presentes en el Sacramento, como señaló el decreto Sobre el Santísimo Sacramento en el capítulo primero: “ (...) se contiene en el saludable sacramento de la santa Eucaristía verdadera, real y substancialmente nuestro Señor Jesucristo, verdadero Dios y hombre, bajo las especies de aquellas cosas sensibles; pues no hay en efecto repugnancia en que el mismo Cristo nuestro Salvador esté siempre sentado en el cielo a la diestra del Padre según el modo natural de existir, y que al mismo tiempo nos asista sacramentalmente con su presencia $(\ldots)^{\prime \prime 14}$.

La figura de Cristo destaca en la composición no sólo por tratarse de una figura muy poderosa, sino por ocupar el lugar central de la misma, reforzándose el sentido cristocéntrico de la doctrina católica sobre la Eucaristía. Por otro lado, la representación de la Trinidad en estampas de motivos eucarísticos no resulta extraña, sino que fue bastante frecuente desde finales del siglo XVI, pueden servirnos de ejemplo la estampa de la prensa mística de Jerónimo Wierix o la primera estampa que ilustra el libro de fray Melchor Prieto que abrió el grabador Alardo de Popma.

La presencia de la Virgen María viene a incidir en su papel en la redención de la $\mathrm{Hu}$ manidad que había sido puesto en duda por los reformadores, pues sin su fiat no habría tenido lugar ésta. La Iglesia va a defender el papel de la Virgen en la redención, poniéndose de manifiesto en numerosas obras de arte. La Trinidad terrenal se completa con la figura de san Juan Bautista que fue un personaje absolutamente fundamental, siendo al mismo tiempo el último de los profetas y el precursor de Cristo. Su asistencia hace hincapié en la naturaleza humana de Cristo y en la unión hipostática con el Verbo divino en la Eucaristía.

Para Freedberg, en el dibujo del joven Zuccaro se puede percibir también la influencia de la obra de su hermano y maestro Taddeo, sobre todo en su manera de asumir la bella maniera rafaelesca ${ }^{15}$.

14 "Decreto del Santísimo Sacramento de la Eucaristía", en "Del culto y veneración que se debe de dar a este Santísimo Sacramento", Capítulo V, Sesión XIII, del 11 de octubre de 1563, en El Sacrosanto y ecuménico..., p. 121.

${ }^{15}$ S. J. FREEDBERG, Pintura en Italia 1500-1600, Madrid, 1978, p. 493. 


\section{LAS ESTAMPAS DEL TRIUNFO DE LA EUCARISTÍA EN LOS LIBROS LI- TÚRGICOS ESPAÑOLES}

Las estampas que vamos a estudiar están claramente influidas por la de Conerlio Cort y Federico Zuccaro, tanto desde el punto de vista iconográfico como compositivo. La llegada a la Península de las estampas de este pintor italiano fue anterior a su establecimiento en la Corte filipina para trabajar en la decoración de El Escorial. Ainaud alude a como en 1580 el pintor lombardo Pietro Paulo de Montalbergo y el mercader italiano, Francesco Testa, asentados en Barcelona, organizaron la venta y distribución en Madrid, vía Sevilla, de un lote de 3.500 grabados estampados en Roma entre los que se incluían 176 salidos de los buriles del grabador flamenco establecido en Roma, Cornelio $\mathrm{Cort}^{16}$. Aunque no indica si entre las estampas de este grabador se encontraba alguna del Triunfo de la Eucaristía a partir del diseño de Federico Zuccaro, no obstante es bastante probable.

En la literatura española de la época se hace referencia a la venta de estampas de Cornelio Cort y Federico Zuccaro, entre otros, Lope de Vega en La Viuda Valenciana, incluye un personaje llamado Valerio que va vestido de mercader de estampas, y pregona:

$$
\begin{gathered}
\text { “¡A la rica estampa fina! } \\
\text { Y a la dama que le dice: } \\
\text { ¡Mostrá! ¿Qué es este papel? } \\
\text { responde: } \\
\text { El Adonis, del Ticiano, } \\
\text { que tuvo divina mano } \\
\text { y peregrino pincel... } \\
\text { Ésta, por vida de Aurelio, } \\
\text { que es de las ricas y finas, } \\
\text { que es de Rafael de Urbinas } \\
\text { y cortada de Cornelios (Cort). }
\end{gathered}
$$

${ }^{16} \mathrm{~J}$. AINAUD, Miniatura y grabado, en "Ars Hispaniae", Madrid, 1958, pp. 270-275; F. CHECA CREMADES, "La imagen impresa en el Renacimiento y el Manierismo", en El grabado en España (Siglos XV al XVIII), "Summa Artis: Historia General del Arte", vol. 31, Madrid, 1996, p. 82.

$$
\begin{gathered}
\text { Ésta es de Martín de Vos } \\
\text { y aquesta de Federico (Zuccaro)"17. }
\end{gathered}
$$

Todas estas estampas se usaron para acompañar el oficio de la fiesta del Corpus Christi en algunos libros litúrgicos del Nuevo Rezado editados en España a finales del siglo XVI y principios del XVII. De sobra es sabido que la festividad del Corpus tuvo su origen en el siglo XIII, en un momento de especial fervor eucarístico vinculado a la llegada a Europa de reliquias de la Sangre de Cristo como las ampollas de la Catedral de Brujas, a las noticias sobre ciertos milagros eucarísticos como el de las formas de Bolsena o a las revelaciones eucarísticas de santa Juliana de Rétiene, que hay que poner en relación con la aparición de algunas herejías que negaban la presencia real de Cristo en el Sacramento $^{18}$. El papa Urbano IV estableció la fiesta del Corpus Christi por la bula Tansiturum de hoc Mundo, el 31 de agosto de 1264, y encargó a santo Tomás de Aquino la composición de su oficio litúrgico, de ahí que sea un personaje bastante frecuente en las representaciones de este motivo y de otros temas relacionados con la Eucaristía.

En el Concilio de Trento se va hacer hincapié en la importancia de esta festividad como un medio de alabar la Eucaristía: "Declara además el Santo Concilio, que la costumbre de celebrar con singular veneración y solemnidad todos los años, en cierto día señalado y festivo, este sublime y venerable Sacramento, y la de conducirlo en procesiones honoríficas y reverentemente por las calles y lugares públicos, se introdujo en la Iglesia de Dios con mucha piedad y religión"19.

\footnotetext{
${ }^{17}$ LOPE DE VEGA, "La Viuda Valenciana", en Comedias escogidas de fray Lope Felix de Vega Carpio, Madrid, 1946, p. 74.

${ }^{18} \mathrm{~J}$. PORTÚS PÉREZ, La antigua procesión del Corpus Christi en Madrid, Madrid, 1993, p. 34.

19 "Decreto sobre el Santísimo Sacramento de la Eucaristía", en "Del Culto y Veneración que se debe de dar a este Santissimo Sacramento", Cap. V, Sesión XIII, 11 de octubre de 1551, en El Sacrosanto y ecuménico..., pp. 128-129.
} 
La fiesta del Corpus se va a convertir en una de las principales del año litúrgico, lo que va a tener su reflejo en los libros litúrgicos adaptados a las nuevas exigencias emanadas de Trento. Este tipo de libros van a estar ornados con estampas que acompañan a las principales fiestas del calendario, entre las que se incluye la del Corpus Chris$\mathrm{ti}^{20}$. El motivo que más comúnmente se empleó para ilustrar dicha solemnidad fue el de la Última Cena; pueden servirnos de ejemplo las numerosas ediciones que del Misal Romano hizo la Imprenta Plantiniana, cuyas estampas se deben a algunos de los grandes artistas y grabadores asentados en la ciudad del Escalda.

Sin embargo, los misales que vamos a estudiar optaron por el motivo del Triunfo de la Eucaristía. La cuestión es, ¿por qué se optó por este motivo? Por un lado, como ya hemos señalado, este tema plasma perfectamente la doctrina de la Iglesia sobre el Sacramento. Además era un motivo que estaba sancionado por uno de los grandes artistas del Renacimiento Clásico, Rafael.

El hecho de que todos estos misales hayan sido impresos en España, nos permite plantearnos una cuestión que ha generado una fuerte controversia entre los especialistas, la existencia o no de un privilegio regio de Felipe II al tipógrafo amberino Cristóbal Plantino para suministrar a la Corona los libros del Nuevo Rezado ${ }^{21}$. En mi opinión, la existencia de estos misales viene a confirmar

${ }^{20}$ M. A. GONZÁLEZ GARCÍA, “El grabado en los libros litúrgicos de uso en España en los siglos XVI y XVII y su influencia en la pintura y la escultura", Cuadernos de Arte e Iconografía, t. IV, no 7, 1991, p. 315.

${ }^{21}$ J. MOLL, "Sobre el privilegio a Cristóbal Plantino", en Homenaje a Justo García Morales. Miscelánea de estudios con motivo de su jubilación, Madrid, 1987, pp. 809-819; ÍDEM, "Plantino, los Junta y el privilegio del Nuevo Rezado", en Simposio Internacional sobre Cristóbal Plantino, Madrid, 1990, pp. 9-23; C. PELIGRY, "La Oficina Plantiniana, los libros litúrgicos y su difusión en España: un caso de estrategia editorial", Simposio Internacional sobre Cristóbal Plantino, Madrid, 1990, pp. 6376; F. ROBBEN, Cristóbal Plantino (1520-1589) y España, Madrid, 1990.

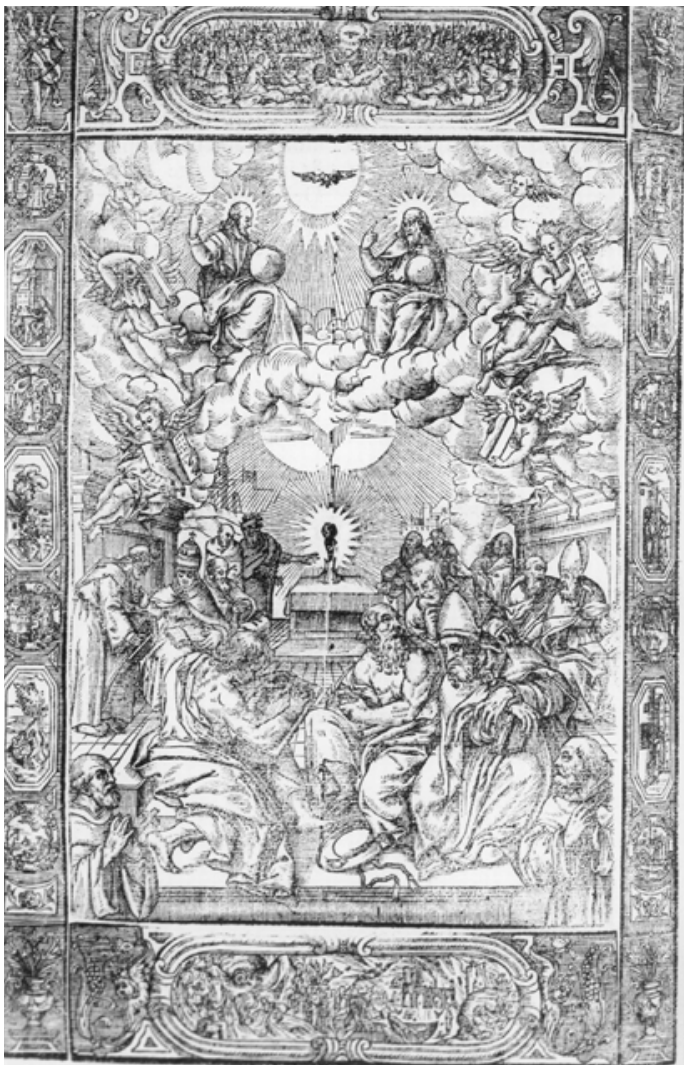

- Fig. 2. Anónimo. "Triunfo de la Eucaristía", Missale Romanum, Salamanca, Guillermo Foquel, 1589. Biblioteca Nacional de España, Sala Cervantes, R/31303. Entalladura, $198 \times 290$ mm.

la hipótesis de que Plantino y sus sucesores, los Moretus, no tuvieron ningún privilegio y se vieron obligados a hacer frente a la feroz competencia de una familia de impresores de origen florentino asentados en España en el último cuarto del siglo XVI, los Junta o Giunta, que desde la década de 1590 van dirigir la Imprenta Real que como vamos a poder comprobar fue la que imprimió buena parte de estos libros.

La primera estampa que vamos a analizar es una entalladura que acompaña al oficio del Corpus Christi en el Missale Romanum, impreso por Guillermo Foquel en Salamanca en 1589 (Fig. 2) ${ }^{22}$. De este impre-

22 BNE, Sala Cervantes, R/31303, 198×290 mm. L. RUÍZ FIDALGO, La Imprenta en Salamanca, Madrid, 1994, vol. 3, pp. 1090-1091; A. ODRIOZOLA, Catálogo de libros litúrgicos españoles y portugueses, impresos en los siglos XV y XVI, Pontevedra, 1996, p. 177. 
sor no se tienen muchos datos antes de su establecimiento en Salamanca a mediados de la década de 1580. Muchos han aludido a su posible origen francés, pero Agulló ha dado a conocer unos documentos que demuestran que nació en Brujas ${ }^{23}$. Se estableció en la ciudad del Tormes con el objeto de imprimir libros litúrgicos, teniendo una estrecha relación con Julio Junta. En los ocho años que estuvo su taller abierto en dicha ciudad al menos 15 de las 44 obras que editó fueron libros del Nuevo Rezado ${ }^{24}$, aunque sobre todo ha pasado a la historia por ser el primero en editar las obras de santa Teresa de Jesús. Destacan sus ediciones del Misal tridentino de 1586, 1587, 1588 y 1589. De la del año 1588 tenemos que destacar que fue la única que incorporó estampas abiertas por medio de la talla dulce, procedimiento poco frecuente en los libros impresos en la Península en estas fechas, pero bastante común en las ediciones amberinas, lionesas y venecianas ${ }^{25}$. Fue relativamente frecuente que un mismo impresor hiciera ediciones de los libros del Nuevo Rezado con estampas abiertas por la talla dulce y otras con entalladuras, puede servirnos de ejemplo Plantino o su sucesor, Jan Moretus ${ }^{26}$. En el año 1593 tenía abierto un taller en Madrid, en el que imprimió algunas obras ${ }^{27}$. Unos documentos dados a conocer por Agulló y Cobo demuestran que falleció en Madrid en 1593, dejando en su testamento como heredera a su esposa

${ }^{23}$ M. AGULLÓ Y COBO, La Imprenta y el comercio de libros en Madrid (Siglos XVI-XVIII), Tesis doctoral defendida en la Universidad Complutense de Madrid, 1991, p. 7; J. DELGADO CASADO, Diccionario de impresores españoles (Siglos XV-XVIII), Madrid, 1996, vol. 1, p. 240.

${ }^{24}$ L. RUÍZ FIDALGO, Op. cit., vol. 1, p.117.

${ }^{25} \mathrm{BNE}$, Sala Cervantes, R/39182. Por desgracia este ejemplar ha perdido la estampa que ilustra la fiesta del Corpus Christi.

${ }^{26}$ K. BOWEN y D. IMHOF, "Book Illustrations by Marteen de Vos for Jan Moretus I", Print Quarterly, vol. 18, no 3, 2001, p. 262; D. IMHOF, The Illustration of Books Published by the Moretus, Antwerp, 2014, vol.1, p. 455.

${ }^{27}$ B. GARCÍA VEGA, El grabado del libro español. Siglos XV-XVI-XVII, Valladolid, 1984, vol. 2, p. 48; L. RUÍZ FIDALGO, Op. cit., vol.1, p. 117.
Isabel Sánchez, dictado el 23 de octubre de ese $a \tilde{n} \mathrm{o}^{28}$. Fue enterrado en el convento matritense del Carmen, según había indicado, figurando la correspondiente partida de defunción en la parroquia de San Martín, el 26 de ese mismo mes $^{29}$. Esto demuestra que es errónea la hipótesis de que fuese contratado por la Imprenta Real que acababa de fundar en la Villa Julio Junta y Modesti, para imprimir las ediciones de los libros del Nuevo Rezado, en lo que Foquel era un experto ${ }^{30}$.

Como sucede en todas las estampas que decoran este misal, ésta carece de las firmas tanto del inventor como del grabador y del editor. El empleo del procedimiento de la entalladura nos lleva a pensar que al menos el grabador debía de ser autóctono, puesto que este era el procedimiento que no sólo dominaban, sino que tenían perfectamente asumido los grabadores españoles de finales del siglo XVI. Que este grabador optase por la entalladura no quiere decir que fuese un artista poco diestro, sino que como demuestra tenía una gran habilidad y dominio de este lenguaje y al mismo tiempo manifiesta su conocimiento de las modas procedentes de los grandes centros artísticos italianos, sobre todo de Roma, y de los grandes maestros del manierismo academicista como es el caso de Zuccaro. En cualquier caso no se le puede considerar un mero artesano.

La estampa tiene una escena central con el motivo de la Adoración del Sacramento y un marco decorativo con una serie de medallones de cueros recortados de marcado gusto manierista en la parte inferior y superior. En el medallón de la parte inferior se repre-

28 Archivo Histórico de Protocolos (en adelante AHP), Mauricio Volineo. Protocolo 1350; 23/10/1593; citado por M. AGULLÓ Y COBO, Op. cit., pp. 188-189; Y. CLEMENTE SAN ROMÁN, Tipobibliografía madrileña. La Imprenta en Madrid en el siglo XVI (1566-1600), Kassel, 1998, vol.1, p. 40.

${ }^{29}$ Archivo de la Iglesia de san Martín, Madrid, Libro de Enterramientos de la parroquia de San Martín de Madrid, 26/10/1593; citado por M. AGULLÓ Y COBO, Op. cit., p. 100; J. DELGADO CASADO, Op. cit., vol.1, p. 241.

${ }^{30}$ L. RUÍZ FIDALGO, Op. cit., vol. 1, pp. 117-118. 
senta el infierno, mientras que en el superior vemos el Cielo. En el infierno al fondo observamos una ciudad envuelta en llamas, mientras en primer plano hay unos demonios que conducen a un nutrido grupo de figuras a la boca del infierno, donde en medio de las llamas está el demonio agarrando con una mano a una mujer a la que agita por los aires y entre las llamas podemos distinguir las cabecitas de algunos de los condenados. Al otro lado vemos a unos seres monstruosos. En los extremos de la parte inferior hay unos motivos decorativos a base de jarrones con flores. En los márgenes laterales se alternan unos recuadros hexagonales y otros circulares con guirnaldas vegetales, en los que se representan algunas escenas bíblicas, aunque son difíciles de distinguir. En el medallón de la parte superior se representa el Cielo con la Trinidad presidida por la paloma del Espíritu Santo, con Cristo y Dios Padre a los lados, con unos nimbos romboidales. Les acompaña la multitud de los santos que portan las palmas del triunfo, entre los que podemos distinguir a san Lorenzo que está en primer plano a la izquierda, al que reconocemos porque tiene la parrilla sobre la que fue martirizado. También vemos como algunos portan mitras con la triple corona que obviamente alude a su rango pontificio. En los recuadros de los ángulos superiores del marco hay una pareja de ángeles mancebos que tañen unos instrumentos musicales, en concreto una viola de gamba y un laúd. Este mismo marco decorativo se usó para enmarcar la estampa de la fiesta de Pentecostés en este misal.

La influencia de la estampa de Zuccaro y Cort resulta obvia, de la que toma el motivo y la estructura de la composición, que se divide en dos partes la celestial y la terrenal, donde se encuentran la Iglesia triunfal y la militante respectivamente, unidas por la Eucaristía. En el centro de la parte terrenal se levanta un altar sobre un peldaño, cubierto por un mantel, sobre el que hay una sencilla custodia en cuyo viril se encuentra la hostia consagrada, rodeada de una aureola de rayos que haría referencia a la presencia divi- na, por tanto se incide en la presencia real de Cristo en el Sacramento, aspecto que habían puesto en duda los reformadores. Al igual que en el fresco de Rafael y en la estampa de Cornelio Cort, este altar constituye el punto de fuga de la composición y a su alrededor tiene lugar un sínodo. Como en la estampa de este último, a los lados observamos unas construcciones que limitan el espacio y conducen la mirada hacia el altar, aunque como iremos viendo presentan diferencias con la obra del flamenco. La presencia de estas construcciones constituye una clara diferencia con el famoso fresco de Rafael que tiene lugar en un amplio paisaje.

Como en la estampa basada en el dibujo del artista italiano, en esta hallamos en primer plano un grupo de figuras de santos que dialogan sobre la Eucaristía. En los extremos hay dos de ellos representados de medio cuerpo, dirigiendo sus miradas hacia el altar en el que se encuentra el Cuerpo de Cristo y que identificamos con san Francisco de Asís y con santo Domingo de Guzmán. Al santo italiano, que está a la izquierda, le distinguimos porque lleva el hábito talar con una gran capucha propio de su orden, tiene una pequeña cruz y en una de sus manos podemos ver la herida que hace referencia a uno de los pasajes más conocidos de su vida, la Estigmatización. Santo Domingo de Guzmán está en el extremo de la derecha, va ataviado con el hábito de los dominicos y sostiene entre sus manos una vara de lirios como símbolo de pureza. La presencia de los fundadores de las Órdenes mendicantes viene a incidir en el fervor de estos dos santos y de las mismas por la Eucaristía que es adorada por ellos y por los demás santos reunidos en este cónclave. No podemos pasar por alto que tras el Concilio, muchas, por no decir todas las órdenes religiosas, tanto las surgidas al calor de la Reforma católica como las de origen medieval, van a tratar de demostrar su fervor por el Sacramento, encontrando entre sus miembros alguno que fuera especialmente devoto del mismo. En el caso de los franciscanos y dominicos, quien mejor que sus propios fundadores. 
En el centro del primer plano, sobre un estrado, en unos bancos dispuestos diagonalmente, encontramos a algunos de los Padres de la Iglesia de occidente, en la misma disposición que la estampa de Cort. La presencia de los Padres de la Iglesia en este cónclave sobre la Eucaristía va a ser muy común; ya los encontrábamos en la obra de Rafael, y vamos a volverlos a ver en las de Rubens y Bloemaert en pleno siglo XVII. La asistencia de este docto cuarteto a este sínodo se debe a que en ellos se fundamenta toda la teología católica, incluyendo la doctrina sobre la Eucaristía, aunque como sus compañeros su principal objeto es la adoración del Sacramento. A la derecha se disponen tres figuras, entre las que se encuentra san Jerónimo que está medio desnudo, con una túnica que deja su pecho descubierto como santo penitente que va a entonar el mea culpa y a golpearse en el pecho como penitencia por las tentaciones de su vida anterior ${ }^{31}$. A sus pies en el suelo vemos el capelo cardenalicio que se va a convertir en uno de sus atributos más frecuentes. Sobre sus piernas podemos distinguir un pergamino desenrollado en el que escribe, sosteniendo en la mano derecha el cálamo y con la izquierda el tintero. De esta manera se trata de hacer hincapié en su faceta de exégeta, humanista y traductor de la Biblia al latín, conocida como la Vulgata que fue la traducción más empleada durante la Edad Media y tras el Concilio de Trento se convertirá en la oficial de la Iglesia católica, prohibiéndose expresamente su traducción a las lenguas vulgares ${ }^{32}$, quizás para hacer frente a las muchas traducciones que se hicieron de la Biblia desde finales del siglo XV, de las cuales una de las más famosas fue la de Lutero. Llama la atención como este santo gira violentamente la cabeza para hablar con un hombre que se encuentra detrás de él. A su lado se halla un santo obispo vesti-

${ }^{31}$ P. MARTINO ALBA, San Jerónimo en el Arte de la Contrarreforma, Tesis defendida en la Universidad Complutense de Madrid, 2003, pp. 351-352.

32 "Decreto sobre la edición y uso de la Sagrada Escritura", Sesión IV, 8 de abril de 1546, en El Sacrosanto y ecuménico..., pp. 35-38. do con su atuendo episcopal con una capa que se engancha con un prendedor a la altura del pecho y con la mitra sobre la cabeza. Indudablemente se trata de san Ambrosio o san Agustín, obispos de Milán e Hipona respectivamente, aunque no hay ningún elemento que nos permita indicar de cuál de los dos se trata. Este santo obispo tiene una postura muy inestable con un fuerte contraposto, pues gira su cabeza hacia la izquierda para dirigir su mirada hacia san Jerónimo, al tiempo que vuelve su torso hacia el lado contrario, tiene sus grandes manos cruzadas sobre un libro cerrado que apoya en una de sus piernas. A la sensación de movimiento contribuyen enormemente los plegados de las telas. Tras ellos hay un hombre, al que resulta muy difícil de identificar, que dirige su mirada hacia san Jerónimo con el que parece estar conversando, al tiempo que apoya una de sus manos en el hombro del obispo y con la otra se acaricia la barba. En el lado izquierdo hay un joven muchacho sentado en un banco, de tres cuartos hacia la derecha, en una postura muy forzada provocada por la disposición de sus piernas. Va vestido con una túnica que le cae desde el hombro izquierdo en unos ricos plegados, y deja desnudo el hombro y el brazo derecho y parte de la espalda; sus piernas están envueltas en una tela de voluminosos pliegues. Este muchacho apoya una tabla sobre una de sus piernas, sosteniéndola con una mano, mientras que con la otra escribe en ella con un cálamo. Esta figura haría las veces de escribano y discípulo que transcribe todo lo que están diciendo los Padres de la Iglesia acerca de la Eucaristía.

A cada lado del altar encontramos a unos hombres que dialogan entre ellos sobre el Sacramento. A diferencia de lo que sucedía con el fresco de Rafael y las estampas que se hicieron a partir de él, o lo que sucederá con la pintura de Rubens y en la estampa de Abraham Bloemaert, aquí resulta muy complicado identificar a cada uno de estos personajes. A la izquierda hay una pareja conformada por un papa y otro hombre. El pontífice está sentado, vestido con un alba y 
una capa pluvial y sobre la cabeza tiene una tiara con la triple corona, sobre sus piernas vemos un libro abierto que sujeta con una mano, mientras con la otra parece señalar a su compañero. Éste está de pie en una postura muy forzada, al inclinarse hacia delante para leer el libro que apoya sobre una de sus rodillas. Va vestido con un alba con amplias mangas sobre la que lleva una especie de casulla, tiene los pies descalzos quizás para señalar que la tierra que pisa es sagrada como Moisés en el Sinaí. Se dispone de perfil como si estuviera atento a lo que le dice el pontífice y sobre sus ondulados cabellos tiene un curioso tocado. El papa podríamos identificarlo con san Gregorio Magno, otro de los Padres de la Iglesia que ha pasado a la historia del arte por el famoso motivo de la Misa de san Gregorio cuya vinculación con la Eucaristía es de sobra conocida. Más allá de las leyendas hagiográficas sobre este milagro, hay que tener en cuenta que san Gregorio escribió varios sermones sobre la Eucaristía y fue el encargado de unificar la liturgia del Sacramento $^{33}$. Tras esta pareja podemos ver un alto pedestal dispuesto en diagonal que nos conduce hacia el fondo como en la estampa de Zuccaro, pero a diferencia de ésta sobre el mismo no vemos las basas y los fustes de unas columnas.

Junto al altar hay una pareja de hombres de pie que dialogan, uno de ellos presenta una postura muy forzada al tener su cuerpo dispuesto de tres cuartos hacia la derecha, pero vuelve la cabeza hacia la izquierda para hablar con su colega, al tiempo que abre sus brazos como señalando a éste y al espectador el altar en el que se encuentra la custodia. El otro hombre tiene el cuerpo ligeramente girado hacia la izquierda, pero se vuelve hacia su compañero para mirar el altar. Ambos van ataviados a la antigua con manto y túnica, lo que nos conduce a pensar que se trata de algún santo de los primeros siglos del cristianismo. En la estampa de Zuccaro, tras estas dos figuras podemos ver un poderoso pilar en el que se abre una hornacina en

\footnotetext{
${ }^{33}$ M. VLOBERG, Op. cit., vol. 2, p. 200.
}

la que se encuentra una escultura que sirve de base al arranque de una bóveda de medio cañón con casetones, mientras que en esta estampa se ha suprimido este elemento arquitectónico. Entre estas dos parejas del lado izquierdo hay otro santo sentado que cruza sus piernas y parece estar meditando. Esta figura presenta en su cabeza ciertas diferencias con la estampa de Cort, puesto que en este caso parece tratarse de un hombre calvo, mientras que en la del flamenco no es así.

En el lado derecho vemos a un obispo hablando con un hombre de larga barba. El obispo que está sentado de frente gira su cabeza hacia la izquierda como si hablara con su compañero. Va vestido con el alba sobre la que lleva la capa pluvial que se engancha con un prendedor y tiene unos profundos plegados, y sobre la cabeza tiene una mitra, con una de sus ínfulas cayéndole sobre un hombro. Sobre sus piernas tiene un libro abierto. La figura presenta un marcado movimiento, al que contribuye el gesto de sus manos. A este obispo podríamos identificarlo con san Ambrosio o san Agustín, completando así el grupo de los Padres de la Iglesia en esta asamblea. Junto a él vemos a un hombre de larga barba, vestido con un manto y una túnica de profundos y voluminosos plegados, que gira su cabeza para hablar con el obispo. Este personaje, como sucede con la mayoría de los que forman parte de este cónclave, resulta imposible de identificar porque no tiene ningún elemento que sea característico de un determinado santo. Tras ellos hay un joven muchacho de pie, ataviado con una túnica, que señala con una mano hacia el altar y que podríamos identificar con el evangelista san Juan, al que comúnmente se le representa en Occidente como un joven imberbe. $\mathrm{Su}$ presencia se debe no sólo a que es uno de los evangelistas, sino sobre todo, a que es el único que recoge el discurso eucarístico tras la multiplicación de los panes ${ }^{34}$. Junto al altar hay una pareja de hombres, uno de ellos está admirando el Sacramento, al tiempo que sujeta con una de sus manos un libro abierto

\footnotetext{
${ }^{34}$ Juan, 6, 22.
} 
que apoya en su cadera y con la otra parece acariciarse la barba. El otro hombre resulta muy difícil de identificar porque los trazos están muy desgastados y borrosos, aunque posiblemente al igual que en la estampa de Zuccaro, se trata de un hombre de larga barba que gira su cabeza hacia el altar.

El fondo presenta ciertas diferencias con la estampa de Cort, puesto que en el lado izquierdo no vemos un edificio en construcción con el tambor de una cúpula y una arquería con un andamio, sino que se trata de un sencillo edificio de varias plantas y otro apenas esbozado. En el lado derecho se ha sustituido el paisaje agreste por otros tantos edificios. Una diferencia notable con la estampa original de Cort, es que las nubes parecen invadir el paisaje del fondo.

Las principales diferencias con la estampa del flamenco las encontramos en la parte celestial, tanto a nivel compositivo como iconográfico. El artista que diseñó esta estampa ha reducido la Iglesia celestial a la Trinidad y a unos pocos ángeles, frente al diseño de Zuccaro en el que están presentes la Trinidad celestial y la Trinidad terrenal, además de numerosos personajes del Antiguo y del Nuevo Testamento y algunos santos. La forma de disponer la Trinidad celestial es distinta a la que veíamos en el fresco de Rafael y en la estampa de Zuccaro, en las que se sigue un eje vertical. En ésta, en la parte superior en medio de un halo de luz se encuentra la paloma del Espíritu Santo con las alas desplegadas, que marca el eje vertical de la composición junto con la custodia del altar. A los lados, sentados sobre unas bandas de nubes, están Cristo y Dios Padre, a izquierda y derecha respectivamente. Ambos tienen sobre una de sus piernas un gran orbe, en el que apoyan una de sus manos, mientras que la otra la levantan, señalando con un dedo hacia el Cielo. Cristo está sentado de perfil, dirigiendo la mirada hacia Dios Padre, va vestido con un manto y una túnica que le cae en voluminosos plegados. Dios Padre está sentado de tres cuartos hacia la izquierda, se le representa como un anciano, de larga barba y calvo, siguiendo un tipo iconográfico muy extendido desde el primer arte cristiano.

Entre el cónclave que tiene lugar en la parte terrenal y la Trinidad de la parte celestial, podemos ver a cuatro ángeles mancebos que portan unas tablas o libros que hacen referencia a los cuatro Evangelios en los que se recoge la doctrina eucarística. Ya en el fresco de Rafael veíamos a unos ángeles portando unos libros, y lo mismo sucedía en la estampa basada en el diseño de Zuccaro, aunque en ambas se disponen a los lados de la paloma del Espíritu Santo que está bajo la figura de Cristo y en sentido horizontal. En el caso del fresco del artista de Urbino se trata de ángeles niños, mientras que en el de la estampa de Cort son ángeles mancebos, como en esta estampa. Sin embargo, en ésta, los ángeles se disponen en parejas a los lados, siguiendo un eje vertical. Estas figuras tienen un fuerte movimiento que se ve potenciado por los pliegues de las telas que envuelven sus cuerpos y por la manera como despliegan sus alas. Estos cuatro ángeles se disponen alternativamente, lo que provoca que la mirada del espectador se centre en la parte central de la composición. A pesar del cambio de posición, tienen un fuerte parecido con los ángeles del diseño de Zuccaro. Su presencia nos lleva a pensar que en el cónclave que está teniendo lugar en la parte terrenal de la composición, están presentes los cuatro evangelistas que por otra parte son los que recogen el principal texto eucarístico, la Última Cena. Entre las bandas de nubes que rodean a la Trinidad podemos distinguir las cabecitas aladas de algunos querubines que dirigen las miradas hacia la Trinidad.

Las otras estampas que vamos a estudiar en este artículo ilustran libros litúrgicos editados por la Tipografía Regia o Imprenta Real, dirigida desde su fundación por los Junta o Giunta, en la que tuvo un papel crucial Julio Junta de Modesti. Esta familia de comerciantes de origen florentino, dedicados al negocio de la edición, impresión y distribución de libros, extendieron rápidamente sus negocios a otras ciudades ita- 
lianas, como Venecia, a uno de los grandes centros editoriales de Francia, Lyon, y a Castilla, donde se establecieron en Salamanca, Burgos, Medina del Campo y Madrid, pero realmente sus agentes llegaban a toda la Península y a los Virreinatos. Algunos han considerado a los Junta una auténtica multinacional de impresores y libreros ${ }^{35}$. Además tuvieron vínculos familiares y comerciales con otros importantes impresores asentados en España como los Gast y los Millis ${ }^{36}$. Los Junta se van a convertir en unos de los grandes proveedores de los libros del Nuevo Rezado al Monasterio de San Lorenzo de El Escorial desde la década de 1570, siendo los competidores más destacados de otra de las grandes empresas editoriales de Europa, el Compás de Oro de Amberes.

El miembro más importante de esta familia asentado en España fue Julio Junta de Modesti, aunque no fue el primero en hacerlo, este honor le corresponde a su tío Juan de Junta que trabajó en Salamanca y Burgos ${ }^{37}$. A este hábil empresario debemos la fundación de la Imprenta Real, como indica Melchor de Cabrera Núñez de Guzmán en su Discurso sobre las Excelencias del Arte de la Imprenta: "Tratando la Magestad del señor Rey Don Felipe Segundo que el Arte permaneciesse en su Corte con toda perfección, llamó a Iulio Iunti, que tenía en Salamanca todas suertes de matrizes excelente, Griegas, Hebreas y de las demás necesarias para el Rezo y Libros de Canto, y otras; con prensas las mejores que de diferentes Reynos pudo juntar; y officiales primorosos, naturales y extrangeros. Diole casa de aposento: honro su offcina y casa con su Real presencia, y con el título de su Impresor, en que sucedió Tomás Iunti, su sobrino, su mujer, y se conserva en sus sucessores" ${ }^{\prime \prime 3}$.

\footnotetext{
${ }^{35}$ J. DELGADO CASADO, Op. cit., p. 350.

${ }^{36}$ M. AGULLÓ Y COBO, Op. cit., p. 143; Y. CLEMENTE SAN ROMÁN, Op. cit., p. 36.

${ }^{37}$ J. DELGADO CASADO, Op. cit., p. 350.

${ }^{38} \mathrm{M}$. DE CABRERA NÚÑEZ DE GUZMÁN, Discurso legal, histórico y político en prueba del origen, progresos,
}

Como indica Cabrera Núñez, el principal objeto de la Imprenta Real era la impresión de los nuevos libros litúrgicos aprobados por el Concilio, aunque no se dedicó a ello en exclusiva como demuestra su gran actividad desde su fundación en 1594, realizando algunas ediciones de gran importancia como la de las obras de san Isidoro, la Gramática de Nebrija o el Catecismo de doctrina christiana ${ }^{39}$. Varios aspectos favorecieron que la Imprenta Real se hiciera cargo de la impresión de los libros del Nuevo Rezado, por un lado, para la Corona suponía dejar de comprar los libros a impresores extranjeros, lo que iba en contra de las pragmáticas que no permitían sacar el dinero de España hacia otros países, y por otro los monjes de El Escorial, que ostentaban el privilegio de distribución de los libros del Nuevo Rezado en Castilla, podían controlar de manera más exhaustiva su producción ${ }^{40}$.

Es posible que el propio Julio Junta de Modesti se percatase de las ventajas que podía tener la impresión de estos libros en España. No podemos pasar por alto que desde poco después de su llegada a España estuvo interesado en surtir a la Corona de dichos libros. En septiembre de 1574 firmó un primer concierto con Juan del Espinar, procurador general de El Escorial, para que hiciese imprimir en Venecia 60.000 Breviarios en $8^{\mathbf{0 4 1}}$. Todo parece señalar que la posición de Julio Junta en relación con la impresión y distribución de los libros del Nuevo Rezado, desde finales de la década de 1570, fue muy favorable, en detrimento de Plantino que se vio muy afectado por el enconamiento

utilidad, nobleza y excelencia del Arte de la Imprenta, Madrid, 1675 , fol. 10v.

${ }^{39}$ B. GARCÍA VEGA, Op. cit., vol. 2, p. 51.

${ }^{40}$ Ibídem.

${ }^{41}$ Citado por C. PÉREZ PASTOR, “Noticias y documentos relativos a la historia y literatura española", en Memorias de la Real Academia Española, t. XIII, Madrid, 1926, pp. 206-207; M. AGULLÓ Y COBO, Op. cit., p. 143; W. PETTAS, A History and Bibliography of the Giunti (Junta) Printing Family in Spain 1526-1628, Delaware, 2005, p. 61. 
del conflicto político-religioso en los Países Bajos. Para poder hacer frente a los importantes encargos de los monjes de El Escorial, contaba con sus redes familiares y comerciales en Lyon y Venecia, de ahí su posible viaje a Italia entre 1585 y $1591^{42}$.

Julio Junta de Modesti en junio de 1594, es decir, prácticamente recién fundada la Imprenta Real, cedió el título de Impresor del Rey a su sobrino Tomás Junta, hijo de Bernardo II Junta, como se desprende de un documento conservado en Archivo Histórico de Protocolos de Madrid: "Escritura de declaración de Tomás de Junta a favor de su tío Julio de Junta, diciendo que S. M. ha hecho merced a Julio del título de su impresor para él o la persona que él nombrare y por ciertos respetos el dicho Julio de Junta ha puesto y pone el dicho officio y merced y ha hecho y hace despachar el título en mi cabeza, en confianza y debajo de que yo haya de hazer y haga escritura de declaración dello"43.

Sin embargo, en otro documento posterior el propio Tomás Junta reconoce que el título, propiedad y beneficios serían para su tío mientras viviese o decidiese otra $\cos a^{44}$. Esto parece demostrar que Julio Junta dirigió la Imprenta Real hasta su muerte ${ }^{45}$, aunque su sobrino ejerciera como impresor. Entre los años 1594 y 1596 Tomás Junta imprimió numerosos libros, pero en ellos no firma como Impresor del Rey, ni hace mención a la Imprenta Real, posiblemente como deferencia a la viuda de Alonso Gómez, que aún conservaba el título de Impresora del Rey ${ }^{46}$, como hace en el Epistolae quae per totum annum leguntur,

${ }^{2}$ M. AGULLÓ Y COBO, Op. cit., p. 144.

${ }^{43}$ AHP, Pedro de Prado. Protocolo notarial 1594, fol. 378v.; citado por C. PÉREZ PASTOR, Op. cit., p. 270, W. PETTAS, Op. cit., p. 69.

${ }^{44}$ C. PÉREZ PASTOR, Op. cit., p. 276; M. AGULLÓ Y COBO, Op. cit., p. 142.

45 AHP, Santiago Fernández. Protocolo notarial 2026, fols. 255r.-261v.; citado por W. PETTAS, Op. cit., pp.178-180.

${ }^{46}$ B. GARCÍA VEGA, Op. cit., vol. 2, p. 51; W PETTAS, Op. cit., pp. 69-70. tam de tempore quam de Sanctis, de 1595, del que hablaremos un poco más adelante.

Otra figura importante en los primeros años de la Imprenta Real, fue Juan Flamenco que aparece en el colofón de la mayoría de los libros editados por ésta hasta la década de 1610. De él se sabe que era de origen flamenco y que había sido discípulo de Julio Junta ${ }^{47}$. Éste le nombró oficial mayor de la Imprenta Real, cargo que ostentó hasta su fallecimiento en 1612. Este cargo tenía gran importancia, porque controlaba el proceso de impresión de los libros, desde la llegada de las remesas de papel de Génova, o las matrices para estampas, hasta la dirección del personal de la imprenta.

Por lo que respecta a las matrices para las estampas que decoraban los misales salidos de la Imprenta Real hasta la muerte de Julio Junta de Modesti, en el inventario que se hizo a su muerte en abril de 1619, se hace referencia tanto a las planchas de cobre como a las matrices de entalladuras: “(...) Figuras finas, tasadas por Diego de Astor, criado de su Magestad. 11 de abril de $1619^{48}$.

Primeramente ocho planchas grandes para el misal folio, viejas, tasadas a veinte $\mathrm{y}$ seis reales cada una, montan ducientos $\mathrm{y}$ ocho reales (...).

(...) Figuras bastas, tasadas por Ysidro Fernández de Córdoba, maestro de imprenta. 15 de abril de 1619 .

(...) Nueve figuras para el misal folio y quarto grande, a doze reales, montan ciento y ocho reales $(\ldots)^{\prime \prime 4}$.

En este mismo documento se alude a dos tórculos para tirar las estampas, lo que

${ }^{47}$ M. AGULLÓ Y COBO, Op. cit., p. 98.

48 AHP, Santiago Fernández. Protocolo notarial 2032, fol. 728r.; citado por J. MOLL, “Tres notas sobre la Imprenta Real", en De la Imprenta al lector. Estudios sobre el libro español de los siglos XVI al XVIII, Madrid, 1994 , p. 138

49 AHP, Santiago Fernández. Protocolo notarial 2032, fol. 730r. y v.; citado por J. MOLL, "Tres notas....", pp. $139-140$ 


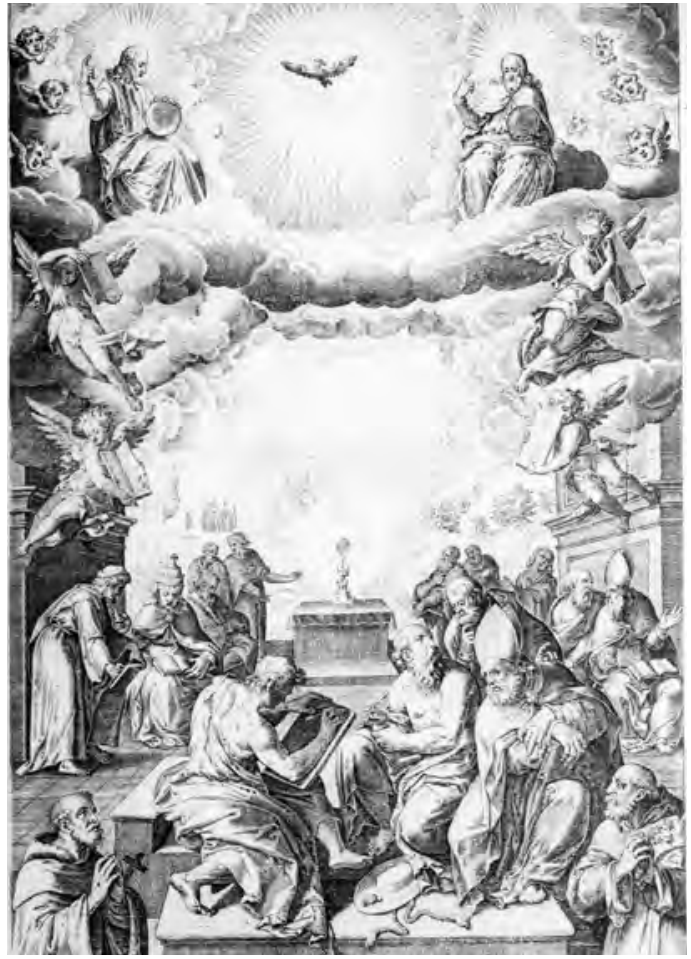

- Fig. 3. Atribuida a Matthäus Greuter. “Triunfo de la Eucaristía", Epistolae quae per totum annum leguntur tam tempore quam de Sanctis, Madrid, Imprenta Real, 1595. Biblioteca Nacional de España, Sala Cervantes, R/26057. Talla dulce, $199 \times 287 \mathrm{~mm}$.

indica que era la propia Imprenta Real la que tiraba las estampas que decoraban sus libros: “(...) Imprenta tasada por Juan de Buet. 8 de abril de 1619.

Yten dos tórculos de estampas finas, tasados en doze ducados entrambos $(\ldots)^{\prime \prime 50}$.

Centrándonos en la que ilustra la fiesta del Corpus del libro Epistolae quae per totum annum leguntur, tam tempore quam de Sancti $^{51}$, con el motivo de la Adoración del Sacramento (Fig. 3). Este libro tiene otras cuatro estampas en las que se representa la Resurrección, Pentecostés, el Martirio de san Lorenzo y la fiesta de Todos los Santos, que acompañan respectivamente a la Pascua,

${ }_{50}$ AHP, Santiago Fernández. Protocolo notarial 2032, fol. 723r. y 724r.; citado por J. MOLL, “Tres notas...", pp. 136-137.

${ }^{51}$ BNE, Sala Cervantes, R/26057, p. 122, 199×287 $\mathrm{mm}$.
Pentecostés, la festividad de san Lorenzo y el día de Todos los Santos. Todas ellas fueron abiertas por medio de la talla dulce que era el procedimiento más usado por los grabadores flamencos, mientras que en España para estas fechas era empleado de manera muy limitada por grabadores extranjeros como Pedro Perret. De las cinco estampas que ilustran este libro, la dedicada al martirio de san Lorenzo se basa en un cuadro con dicho motivo realizado por Tiziano que se encontraba en el Real Monasterio de San Lorenzo de El Escorial y que abrió Cornelio Cort. De las otras cuatro sólo la última tiene la firma de uno de los artistas que intervino en su realización, el grabador Matthäus Greuter (M.G.F), al que se pueden atribuir las otras tres, debido a su semejanza desde el punto de vista técnico.

Este abridor de láminas nacido en Estrasburgo, nunca llegó a viajar a España. Se sabe que trabajó primero en Francia, concretamente en París y Lyon, y en 1606 se trasladó a Roma, dedicándose principalmente al grabado de reproducción, y en donde falleció en 1638. Por la fecha en la que Tomás Junta editó este libro, 1595, y teniendo en cuenta que la dinastía de los Junta había establecido una sede en Lyon hacia 1530, fundada por Giacomo Giunta que mantuvo una estrecha relación con la rama española de Juan de Junta establecida en Salamanca ${ }^{52}$, podemos pensar que el grabador estrasburgués recibió el encargo de abrir estas planchas cuando estaba trabajando en la ciudad francesa. No hay que olvidar que Lyon era junto con París el gran centro editorial francés, siendo uno de los más importantes de Europa y abasteció habitualmente al mercado hispano. Que Tomás Junta recurriese a las matrices abiertas por un grabador extranjero tampoco resulta extraño, puesto que en España no había muchos grabadores en metal. Posteriormente para la ilustración de muchos de sus libros sí que recurrirá a

\footnotetext{
${ }^{52}$ Sobre el desarrollo de la firma Junta en Lyon es muy esclarecedor el apartado que le dedica W. PETTAS, Op. cit., pp. 12-18.
} 
grabadores foráneos asentados en España, principalmente en Madrid.

Desde el punto de vista iconográfico sigue el modelo de la estampa de Zuccaro y Cort, teniendo un gran parecido con la estampa que ilustraba la edición del Missale Romanum de Guillermo Foquel. Como en las anteriores se representa el Triunfo de la Eucaristía que es adorada por la Iglesia terrenal y la celestial, vinculadas por la custodia con la Hostia en la que está Cristo en cuerpo y alma, hombre y Dios al mismo tiempo, cómo señaló el Concilio. En la parte terrenal hallamos ese cónclave de santos que dialogan sobre el Sacramento cómo hemos visto en las anteriores. En esta parte no apreciamos diferencias muy notables con la estampa del Misal de Foquel. Sin embargo, en la parte celestial sí que encontramos algunas diferencias tanto a nivel compositivo como iconográfico con la estampa del misal salmantino. En medio del rompimiento de gloria se encuentra la Trinidad, representada por Cristo y Dios Padre sentados sobre unas bandas de nubes a izquierda y derecha, con la paloma del Espíritu Santo en el centro rodeada de una mandorla de luz. Pero en este caso, las figuras de Cristo y Dios Padre se desplazan hacia los extremos y no están tan centradas como en la estampa que ilustra el libro de Foquel. Esto obliga a desplazar a los dos ángeles mancebos de la parte superior que en la de Salamanca estaban casi a la altura de las figuras de la Trinidad, mientras que aquí están a sus pies. Entre las bandas de nubes que hay a la espalda de las figuras de la Trinidad vemos varias cabecitas aladas de querubes, mientras que en la estampa salmantina sólo había una a cada lado. La diferencia más notable es a nivel iconográfico, pues Dios Padre y Cristo se representan siguiendo el tipo iconográfico de la segunda persona de la Trinidad, mientras que en la estampa que ilustra el Misal de Foquel, Dios Padre sigue el tipo del anciano. El representar a Dios Padre siguiendo la iconografía de la segunda persona de la Trinidad tiene su origen en la
Edad Media ${ }^{53}$, siendo muy frecuente en el siglo XII. Como ha señalado Mocholí Martínez en una reciente publicación, este tipo iconográfico no fue tan habitual a partir del siglo XVI, pero se siguió empleando y pone como ejemplo el Breviario Grimani o La Gloria de Tiziano en el Prado ${ }^{54}$. Ambas figuras tienen el orbe del universo y señalan con un dedo al cielo, pero varían en sus posturas. Cristo está sentado de perfil, va vestido con un manto y una túnica de profundos plegados, tiene la mano izquierda apoyada sobre la parte superior del orbe y con la izquierda señala al cielo. Dios Padre está sentado de tres cuartos hacia la izquierda, su vestimenta varía respecto a la del Hijo, pues lleva una capa que se engancha con un prendedor; también varía la forma en la que sostiene el orbe con la mano izquierda, bajo éste, y con un dedo de la mano derecha señala al cielo.

La reutilización de las matrices de las estampas fue una práctica relativamente frecuente que permitía abaratar los costes de una edición, quizás uno de los ejemplos mejor documentados es el de los Moretus, que contrataron a Theodoor Galle para que retallase algunas de las matrices de las estampas del Misal. La Imprenta Real no fue ajena a esta práctica de reutilización o de realización de nuevas matrices a partir de otras anteriores, como demuestran las estampas que ilustran la festividad del Corpus Christi de dos ediciones del Misal de la imprenta madrileña de la década de 1610, se trata de las ediciones del año 1611 (Fig. 4) 5 $^{55}$ y la de $1618^{56}$. En ambas ediciones encontramos estampas idénticas a la de Matthäus Greuter, aunque tienen tamaños diferentes, lo que nos lleva

\footnotetext{
${ }^{53}$ L. RÉAU, Op. cit., t. 1, vol. 1, pp. 46-47.

${ }^{54}$ M. E. MOCHOLÍ MARTÍNEZ, “La Trinidad del salterio", en el capítulo "Los tipos de la Trinidad", en Los tipos iconográficos de la Tradición cristiana, vol. 1, Madrid, 2015, pp. 488-489.

${ }^{55}$ BNE, Sala Cervantes, 2/13761, p. 416, 165×242 mm.

${ }^{56}$ Universidad Complutense de Madrid, Biblioteca Histórica Marqués de Valdecilla, Biblioteca Histórica de Derecho 9873(1), 150×211 mm.
} 


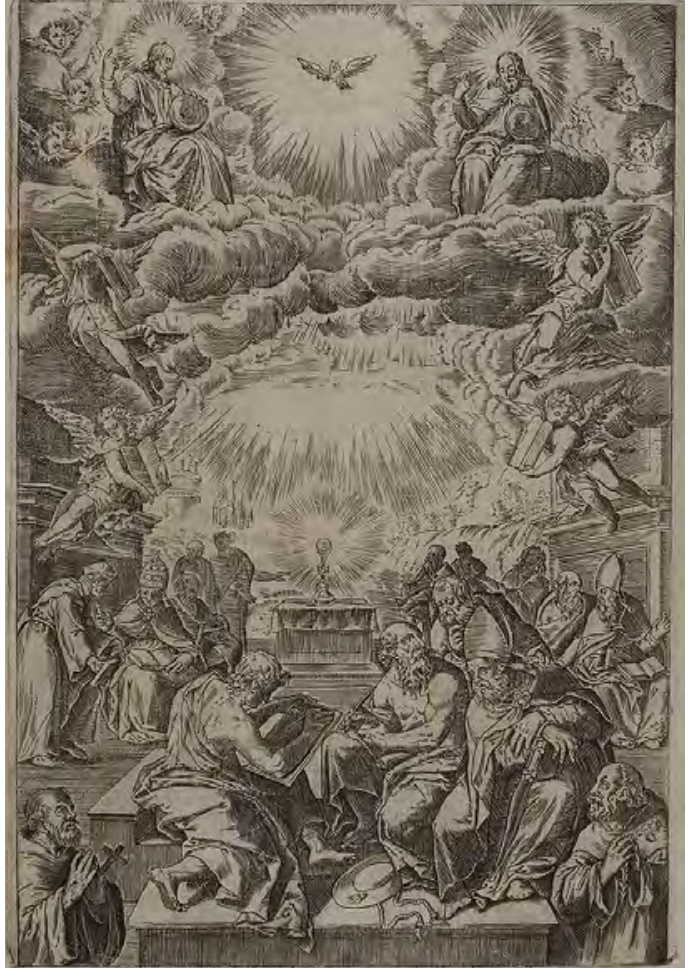

- Fig. 4. Anónimo. "Triunfo de la Eucaristía", Missale Romanum, Madrid, Imprenta Real, 1611. Biblioteca Nacional de España, Sala Cervantes, 2/13761. Talla dulce, $165 \times 242 \mathrm{~mm}$.

a pensar que se obtuvieron a partir de distintas planchas que reproducen la obra del grabador estrasburgués. Ninguna de las dos está firmada, lo que dificulta enormemente la identificación del posible grabador. Pero teniendo en cuenta que fueron abiertas por medio de la talla dulce, que era el procedimiento más común entre los grabadores extranjeros asentados en la corte española, nos deja dos opciones, o fue alguno de ellos el que abrió la estampa o se trajo la matriz desde Francia. En ningún caso se podría pensar en un grabador autóctono, pues en estas fechas los grabadores españoles usaban el procedimiento de la entalladura que era el único que tenían plenamente asumido. Desde el punto de vista iconográfico no hay ninguna diferencia con la estampa de Matthäus Greuter.

Otra obra salida de las prensas de la Imprenta Real es el Missale Cantorale Proprium

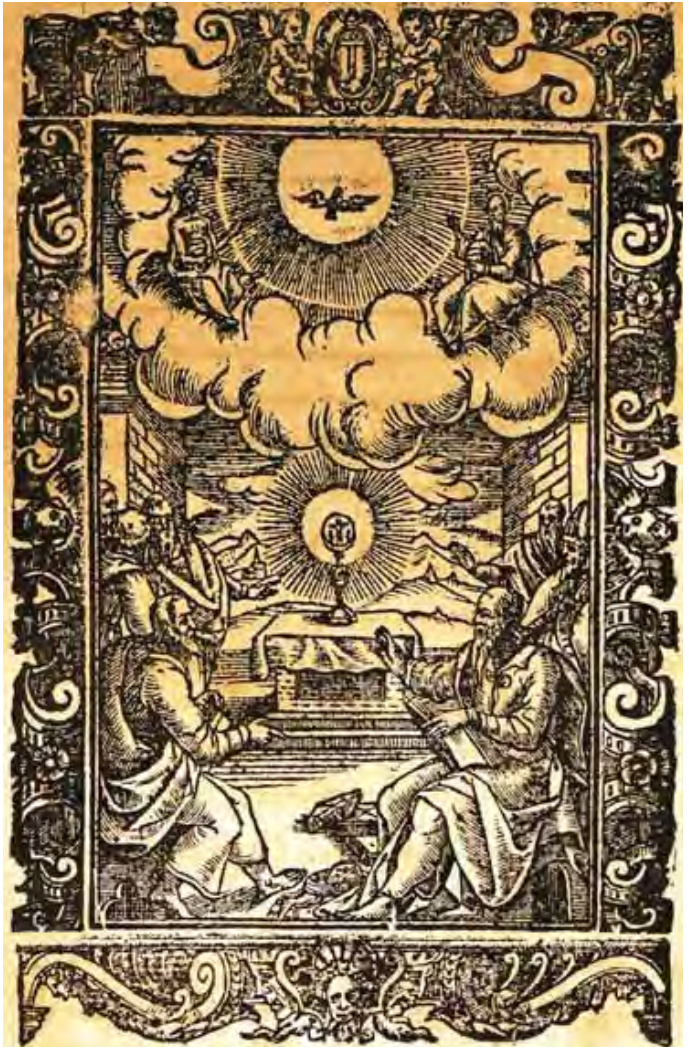

- Fig. 5. Anónimo. "Triunfo de la Eucaristía", Missale Cantorale Propium Missarum, Madrid, Imprenta Real, 1597. Universidad de Salamanca, Biblioteca General/42203. Entalladura, $94 \times 148 \mathrm{~mm}$.

Missarum $^{57}$, fechado en 1597, luego anterior a las dos ediciones del Missale Romanum que acabamos de mencionar. Al contrario de lo que veíamos en el Epistolae quae per totum annum leguntur, tam de tempore quam de Sanctis, en este libro Tomás Junta ya figura como Impresor Real y en el colofón aparece el nombre de Juan Flamenco. Entre las múltiples estampas que ilustran este libro tenemos que destacar la que acompaña a la partitura del Introitus de la fiesta del Corpus Christi, en la que nuevamente se recurre al motivo de la Adoración de la Eucaristía (Fig. 5). A diferencia de la estampa de Matthäus Greuter y de las que ilustraran los misales de 1611 y 1618 , se trata de una entalladura de pequeño formato $^{58}$. Como todas las estampas que ilu-

\footnotetext{
57 Universidad de Salamanca, Biblioteca General 42203.

${ }^{58} 94 \times 148 \mathrm{~mm}$
} 
minan este libro tiene un marco decorativo de gusto manierista, rematado por un escudo con una cruz, sostenido por una pareja de ángeles niños sentados a los lados.

A nivel compositivo e iconográfico sigue el modelo de Zuccaro y Cort como hemos visto en las anteriores estampas, pero muy simplificado. Se estructura en dos partes la terrenal y la celestial, separadas por una banda de nubes que ocultan y al mismo tiempo muestran y visualizan la divinidad ${ }^{59}$. Como en el fresco rafaelesco del Vaticano, en la estampa de Zuccaro o en las que ilustran los distintos libros litúrgicos editados en España, la Eucaristía, representada por una custodia dispuesta en un altar en el centro de la composición, no sólo sirve de punto de fuga, sino que es el nexo entre la parte terrenal y la celestial, incidiendo en la doctrina católica sobre el Sacramento. En esta custodia hay una hostia en la que aparece el Calvario con Cristo en la cruz, flanqueado por la Virgen y san Juan, está rodeada de un halo luminoso que incide en la presencia de Cristo en cuerpo y alma en la Eucaristía, idea en la que había incidido el Concilio tridentino. A diferencia de lo que hemos visto en las anteriores estampas, el altar no está en el fondo del espacio en el que se celebra el sínodo, sino más bien en un segundo término.

En la parte terrenal tiene lugar ese concilio en el que se discute sobre la presencia real de Cristo en el Sacramento y la transubstanciación, que fueron dos aspectos muy criticados por los reformadores. En esta estampa el número de personajes que participan en el cónclave es muy inferior al que veíamos en las anteriores estampas. En ella no vemos al grupo central de los Padres de la Iglesia como en la estampa de Cort o en las que ilustran el Misal de Guillermo Foquel o en la atribuida a Matthäus Greuter. En primer plano hallamos a dos hombres sentados dispuestos de perfil que dirigen sus miradas hacia el altar, al tiempo que dialogan sobre este sacramento. El de la derecha apoya so-

${ }^{59} \mathrm{~V}$. I. STOICHITA, El ojo místico: pintura y visión religiosa en el Siglo de Oro español, Madrid, 1996, pp. 81-82. bre sus piernas un libro abierto que sujeta con una de sus manos, mientras que la otra la extiende hacia el altar. Va vestido con unas telas de voluminosos plegados que cubren parte de la silla en la que se sienta. A sus pies hay un capelo cardenalicio que nos lleva a identificarle con san Jerónimo, a lo que también contribuye su rostro consumido con barba. La presencia de este Padre de la Iglesia en este tipo de representación, como ya hemos visto, no fue para nada extraña. Su compañero también tiene sobre sus piernas un libro que sujeta con una mano, aunque sólo lo vemos parcialmente, porque nos lo tapa su otro brazo que extiende para señalar al suelo, quizás a los libros y mitra que hay en segundo plano tras la figura de san Jerónimo. Lleva una túnica y un manto que cae en unos voluminosos pliegues a un lado. La postura forzada de sus piernas nos trae a la memoria las del joven escribano de la estampa de Zuccaro, sobre todo la pierna izquierda, pero no tienen tanto movimiento como las de esta figura. Este podría ser otro de los Padres de la Iglesia, aunque no tiene ningún elemento que nos permita identificarle. Ambos personajes tienen sus pies descalzos, lo que hace alusión al pasaje bíblico de Moisés ante la zarza ardiente, que se descalza al pisar tierra sagrada.

En segundo plano se encuentran otros tantos personajes que dialogan sobre el Sacramento, que varían tanto en su número como en su disposición respecto a la estampa de Cornelio Cort. En el lado izquierdo tras la figura del primer plano, encontramos a tres hombres que conversan. El que está de espaldas podemos identificarle con un monje porque va vestido con un hábito con una capucha y tiene su cabeza tonsurada. Parece estar hablando con su compañero de enfrente, que tiene una larga barba y extiende una de sus manos hacia el altar, señalando la Eucaristía. Del tercero vemos sólo parte de su rostro, puesto que se encuentra en el extremo de la izquierda y nos lo tapa el monje, se dispone de perfil y observa a sus colegas. En el extremo de la derecha hay un par de figuras, una de ellas es un obispo, al 
que identificamos porque va vestido con una capa pluvial que se engancha a la altura del pecho con un prendedor y tiene sobre su cabeza una mitra. La presencia de obispos en estas escenas, como hemos visto, es habitual, se les suele identificar con san Ambrosio o san Agustín, Padres de la Iglesia. El otro es un hombre de larga barba, está levemente girado hacia la izquierda y extiende una de sus manos hacia el altar en el que está la custodia.

A los lados vemos unos elementos arquitectónicos, como había hecho Cort en la estampa a partir del diseño de Zuccaro o como vemos en la estampa que ilustra el Misal de Foquel, pero en este caso no responden al gusto manierista de los anteriores, sino que son unas estructuras sencillas a base de sillares. Estos elementos nos conducen a un paisaje en el que observamos algunas montañas y un edificio en el lado izquierdo.

En la parte celestial se encuentra la Trinidad como es característico de este tipo de escenas. Como en la estampa con este mismo motivo del Misal de Guillermo Foquel y en la del Epistolae editado por el propio Tomás Junta, la Trinidad no se dispone siguiendo un eje vertical como habían hecho Rafael y Zuccaro, sino que en el centro está la paloma del Espíritu Santo en medio de una aureola de rayos que se extienden hacia los lados, y sentados a los lados sobre unas bandas de nubes, están Cristo y Dios Padre, a izquierda y derecha respectivamente. Cristo se dispone de tres cuartos hacia la derecha, dirigiendo su mirada hacia Dios Padre, parece estar extendiendo uno de sus brazos, va vestido con un manto que deja descubierto su torso, quizás para mostrar la herida del costado. Esto supone una clara diferencia con las estampas del misal salmantino y del Epistolae, en las que Cristo va vestido con una túnica y un manto. Dios Padre se representa como un hombre entrado en años y no como la segunda persona de la Trinidad como veíamos en la estampa de Greuter. Está sentado de tres cuartos hacia la izquierda, extiende la mano derecha hacia arriba como señalando al Espíritu Santo, mientras que con la otra parece sujetar una tiara con la triple corona que es uno de sus atributos más comunes.

Esta estampa carece de las firmas del inventor, del grabador y del editor. El hecho de que se trate de una entalladura nos lleva a pensar en que puede deberse a un grabador autóctono, que como ya hemos señalado en estas fechas era el único procedimiento del grabado que realmente dominaban. Además esta técnica tenía una ventaja sobre la talla dulce y es que se podían imprimir al mismo tiempo el texto y la imagen, cosa imposible en el grabado sobre plancha de cobre. Desde el punto de vista técnico es una obra de calidad, aunque por lo desgastado de los trazos podemos señalar que la matriz había sido usada con frecuencia. Hemos de tener en cuenta que en la época se solían usar los tacos hasta su extenuación y después podían ser retallados para seguir utilizándose, con el único fin de abaratar los costes. El procedimiento de la entalladura ya lo hemos visto empleado en la estampa del Misal de Guillermo Foquel, aunque ésta era de una mayor calidad técnica.

Para concluir, en este artículo hemos abordado el estudio de algunas estampas con el motivo del Triunfo de la Eucaristía que se emplearon para ilustrar algunos libros litúrgicos editados en España, después del Concilio de Trento. Como hemos comprobado, la elección del tema no fue aleatoria, sino que responde claramente al espíritu tridentino, en el que la defensa de la doctrina eucarística se convierte en una de sus piedras angulares. Además, estas estampas van a acompañar a la liturgia de la fiesta del Corpus que estaba destinada a la exaltación y adoración de la Eucaristía, y en la que había hecho hincapié el Concilio. Por otro lado, este motivo había sido representado por uno de los grandes maestros del Renacimiento clásico, Rafael, en la Stanza della Segnatura en el Vaticano, es decir, en el corazón mismo de la Iglesia. Pero como hemos podido comprobar, las estampas que ilustran estos libros no se inspiran en el modelo rafaeliano, sino que parecen imitar el ejemplo de una estampa diseñada por Federico Zuccaro, abierta 
por el grabador flamenco asentado en Roma, Cornelio de Cort. Aunque todas siguen este modelo, presentan ciertas diferencias entre ellas, tanto a nivel técnico, pues algunas fueron abiertas por medio de la entalladura, mientras que otras lo fueron por la talla dulce, como compositivo e iconográfico.

Por otro lado, salvo el Misal editado por Guillermo Foquel en Salamanca, todos los demás libros litúrgicos a los que nos hemos referido salieron de la Imprenta Real, diri- gida por los Junta, que se convirtió en una de las principales firmas que imprimieron y distribuyeron los libros del Nuevo Rezado para Castilla. Los Junta fueron uno de los más importantes competidores de la Imprenta Plantiniana a la hora de suministrar dichos libros a la Corona. La existencia de estos libros litúrgicos viene a demostrar que es errónea la hipótesis de que Plantino y sus sucesores, los Moretus, tuvieran un privilegio de exclusiva de estos libros. 